\title{
Processing of pro-opiomelanocortin-derived amidated joining peptide and glycine-extended precursor in monkey pituitary
}

\author{
Mogens Fenger \\ Mental Health Research Institute, University of Michigan, Ann Arbor, MI 48109 (U.S.A.) and National Institutes of Health, \\ Bethesda, MD 20892 (U.S.A.)
}

(Received 26 July 1990; Revised version received 27 November 1990; Accepted 29 November 1990)

Key words: Proopiomelanocortin; Joining peptide; Monkey; Primate; Amidation; Glycine-extended; Pituitary; ACTH

\begin{abstract}
The molecular forms of proopiomelanocortin (POMC) derived amidated and C-terminal glycine-extended joining peptide from monkey ( $M$ acaca mulatta) pituitary were determined. The predominant forms of joining peptide found were the low molecular peptides POMC(76-105) and POMC(76-106), respectively. Significant amounts of N-terminally truncated POMC(78-105) and POMC(78-106) were also detected in the posteriorintermediate lobe. No N-terminal extended forms were detected. The relative amount of amidated joining peptide to total joining peptide was 6-35\%. It is concluded that not only is the primary sequence of monkey and human POMC extremely conserved, but also the processing patterns are similar. The monkey therefore serves as a suitable model for studying regulation of the processing of POMC and the hypothalamus-pituitary-adrenal axis in man.
\end{abstract}

Proopiomelanocortin (POMC) has served as an excellent model to study the maturation of precursors of regulatory peptides. Comparative studies across tissues and species point to some of the elements, which determine the pattern and extent of processing $[1,6,10,11$, $13,14,16,18]$. Generally, the precursor is initially cleaved at the C-terminal side of ACTH (Fig. 1) followed by cleavage at the $\mathrm{N}$-terminal side. This universal pattern of cleavage releases ACTH from the precursor along with N-terminal POMC (N-POMC) and $\beta$-lipotropin $(\beta$-LPH). Successive cleavage of $\beta$-LPH to $\beta$ endorphin $(\beta \mathrm{EP})$ and $\mathrm{ACTH}$ to $\alpha \mathrm{MSH}$ is tissue specific $[7,18]$.

It is now clear that what has been detected as $16 \mathrm{kDa}$ $\gamma_{3} \mathrm{MSH}$-immunoreactivity mainly consists of the most $\mathrm{N}$-terminal part of POMC (POMC(1-76) in human) in which the fragment linking the $\gamma_{3} \mathrm{MSH}$ sequence with ACTH, i.e. the joining peptide, has been removed. This has been confirmed by studies of the molecular forms of joining (or hinge) peptide in human [2, 11], rat and mouse pituitaries [9], and rat hypothalamus [7]. In these tissues the joining peptide is almost fully processed. Only

Correspondence: M. Fenger, Department of Clinical Chemistry KK 3011, Rigshospitalet, Blegdamsvej 9, DK-2100 Copenhagen, Denmark. the rat anterior lobe appears to store significant amounts of fully $\mathrm{N}$-terminal extended joining peptide [9].

Studies of the amidated joining peptide and its C-terminal glycine-extended precursor have now been extended to the monkey pituitary. The monkey POMC resembles the human POMC closely, in that all the putative $\alpha$-amidated peptides are present in the precursor [17], which is not the case in any other species. Monkey POMC can therefore serve as a model system for studies of the synthesis and regulation of human POMC in vivo as well as in vitro.

Pituitaries from Macaca mulatta $(n=6)$ were dissected into anterior and posterior-intermediate lobes while kept frozen on dry ice. POMC-related peptides were extracted in boiling water and acetic acid as previously described [11]. Combined water and acetic acid extracts were applied to molecular sieve chromatography on $1.6 \times 87 \mathrm{~cm}$ bioGel P10 columns (Biorad, Richmond, CA) and eluted at room temperature in $0.5 \mathrm{M}$ acetic acid. Peak fractions of joining peptide were applied to an analytical Nucleosil $\mathrm{C}_{18}$-reverse phase HPLC at room temperature and were eluted by a gradient of acetonitril in $10 \mathrm{mM}$ trifluoric acetic acid (TFA). The eluted joining peptide immunoreactivities were subjected to automated amino acid sequence analysis [11].

Radioimmunoassays for amidated joining peptide were performed as previously described $[10,11]$. The as- 


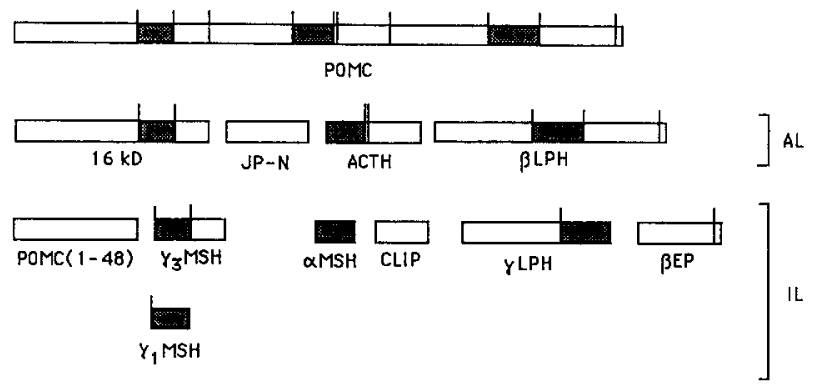

Fig. 1. Processing pattern of proopiomelanocortin (POMC) in the anterior lobe (AL) and intermediate lobe (IL) of the pituitary gland. The vertical lines indicate dibasic amino acids and the hatched areas indicate the $\mathrm{MSH}$-sequences. $\beta$ - $\mathrm{LPH}, \beta$-lipotropin; $\beta \mathrm{EP}, \beta$-endorphin; JP-N, amidated joining peptide; CLIP, corticotropin-like intermediate lobe peptide. The vertical line on the $\mathrm{N}$-terminal side of $\gamma_{3} \mathrm{MSH}$ and $\gamma_{1} \mathrm{MSH}$ indicates that these peptides have been identified also as Lys$\gamma$ MSH peptides. The C-terminal glycine extended intermediate forms of the amidated peptides $\left(\gamma_{1} \mathrm{MSH}, \mathrm{JP}-\mathrm{N}\right.$ and $\left.\alpha \mathrm{MSH}\right)$ have been omitted from the figure.

say is specific to joining peptide and the cross-reactivity to the glycine-extended precursor is less than $0.02 \%$ at half-maximum displacement of the tracer. No other POMC-related peptides were detected by the assay. A new radioimmunoassay for glycine-extended joining peptide was developed essentially as described [10, 11], in which a glycine-extended truncated form of joining peptide (D-Tyr-Ala-Lys-Pro-Gly-Pro-Arg-Glu-Gly) was used as immunogen, tracer and standard [11].

The new assay for glycine-extended joining peptide was specific for the glycine-extended form of joining peptide with cross-reactivity of less than $0.01 \%$ of the amidated form (not shown). No other POMC-derived peptides were recognized by the assay. The sensitivity of the assay was $1 \mathrm{fmol}$.

The relative amount of amidated joining peptide varied from $6 \%$ to $35 \%$. The elution of anterior pituitary joining peptide immunoreactivities from BioGel P10 columns is shown in Fig. 2. The majority of the joining peptide immunoreactivities eluted as single peaks. A small amount of immunoreactivities eluted approximately in the middle of the column, but no immunoreactivity was detected in the void volume and none eluted after the elution position of ACTH(1-39). A similar elution profile was detected from the posterior-intermediate lobe (not shown).

The major amidated joining peptide immunoreactive peaks (Fig. 2, $K_{\mathrm{av}}=0.36$ ) from anterior and posteriorintermediate lobes were applied to reversed phase HPLC as shown in Fig. 3. The immunoreactivities eluted essentially in single peaks. However, the amidated joining peptide immunoreactivity from the anterior lobe eluted at a significant higher concentration of acetonitrile ( $50 \%$, upper figure) compared to the posterior-intermediate lobe (37\%, lower figure). A small amount of immunoreactivity eluted at $20 \%$ acetonitril (fraction 20 ) from both lobes. This coincided with the elution position of the smaller peaks of amidated joining peptide (Fig. 2, $K_{\mathrm{av}}=0.57$ ), when applied to HPLC (not shown).

The immunoreactive peaks shown in Fig. 3 were subjected to amino acid sequence analyses and proved to be pure enough to determine the sequence of joining peptide unambiguously (Table I). The major peak from the anterior lobe contained only the low molecular form of joining peptide generated by cleavage of N-POMC Cterminal to $\gamma_{3} \mathrm{MSH}$. Approximately two thirds of the amidated joining peptide in the major peak from the posterior-intermediate lobe was identical to the joining peptide from the anterior lobe, the remaining one third being low molecular weight amidated joining peptide in which the amino-terminal glutamate and aspartate have been removed. The amino acid sequence analysis of the minor amidated joining peptide peaks in Fig. 2 (and
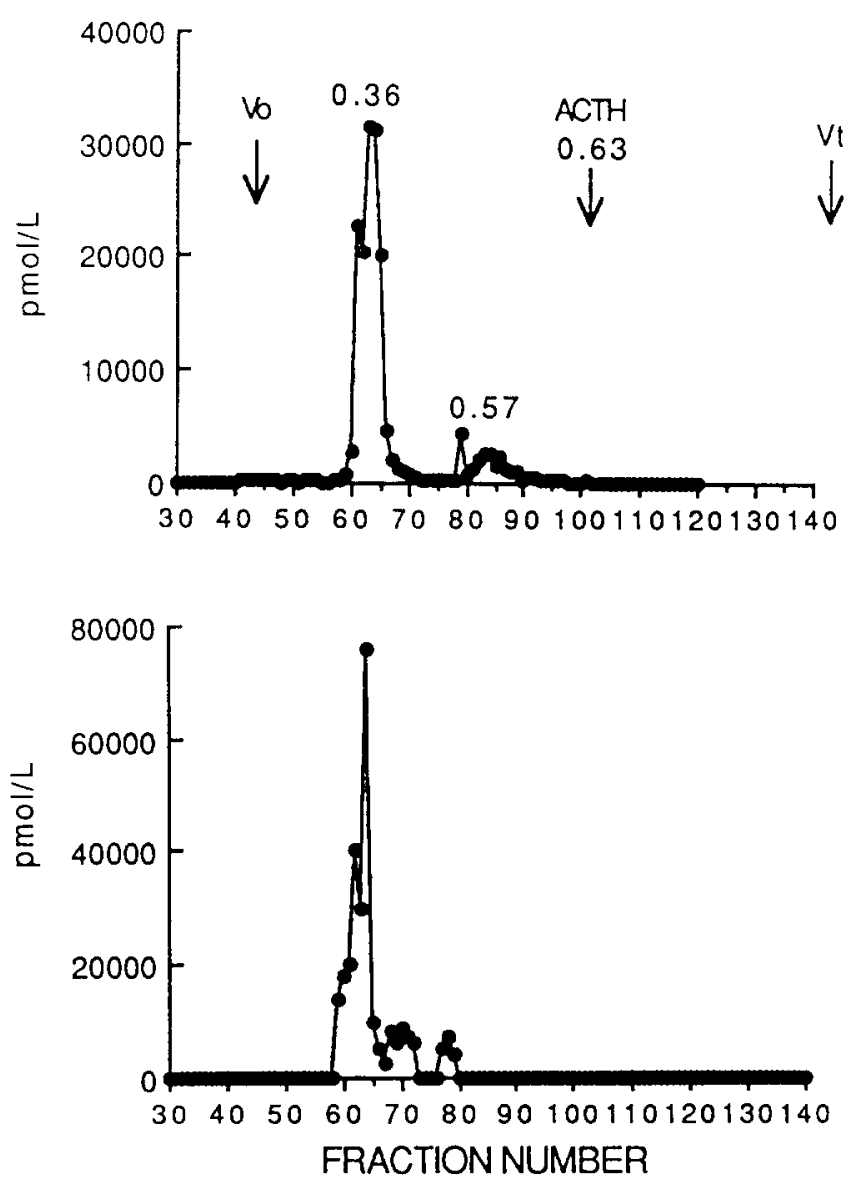

Fig. 2. Elution of amidated (upper panel) and glycine-extended (lower panel) joining peptide from an anterior pituitary lobe on a $1.6 \times 87$ $\mathrm{cm}$ BioGel P10 column in $0.5 \mathrm{M}$ acetic acid at room temperatur. Approximately half of the pituitary extracts were applied to the column, and $1.5 \mathrm{ml}$ fractions were collected. The peaks eluting at $K_{\mathrm{av}}=$ 0.36 and $K_{\mathrm{av}}=0.57$ were further purified by HPLC (Fig. 3). $K_{\mathrm{av}}=$ $V_{\mathrm{e}}-V_{0} / V_{\mathrm{t}}-V_{0}$ where $V_{\mathrm{e}}$ is the elution position of the peptides. 

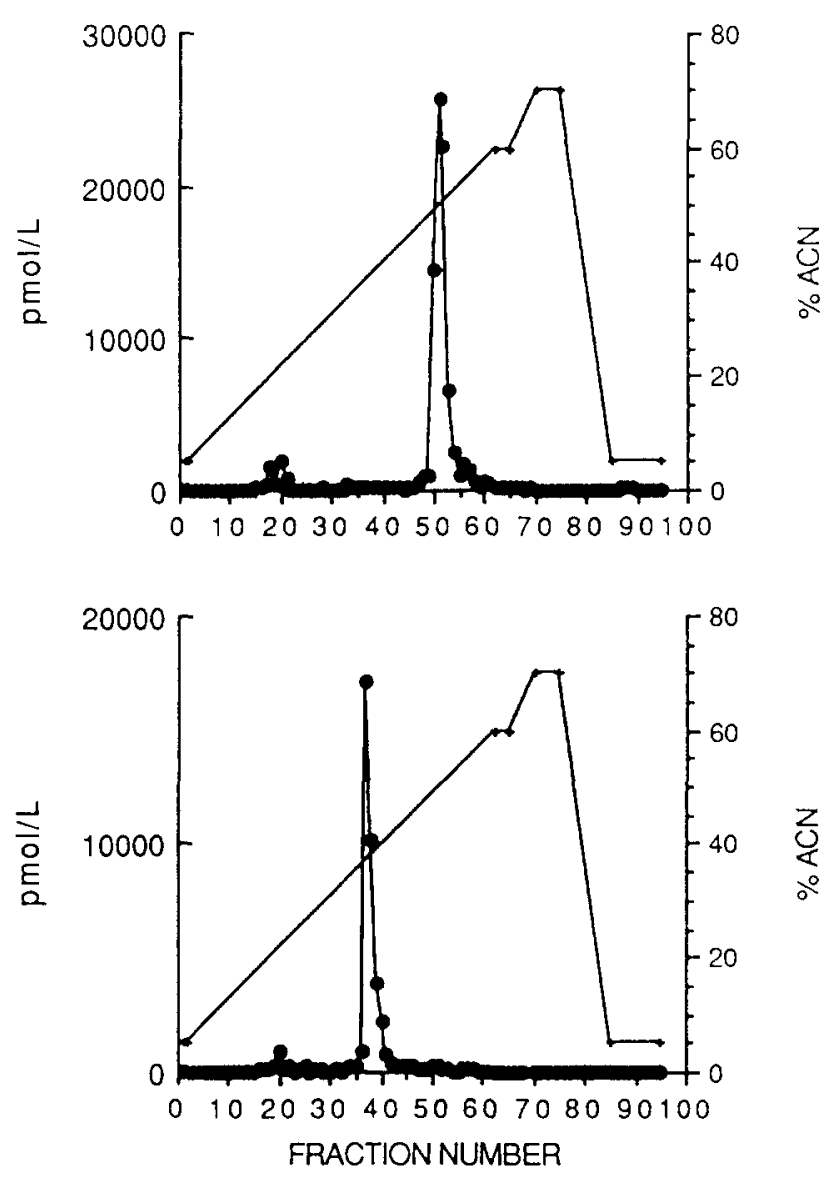

Fig. 3. Purification of the major amidated joining peptide peak indicated in Fig. 2 (upper panel) and a similar peak from posterior-intermediate lobe (lower panel). The peptides were applied to a $4 \times 250$ $\mathrm{mm}$ Nucleosil $\mathrm{C}_{18}$ reversed phase HPLC column and eluted at room temperature at a flow rate of $0.5 \mathrm{ml} / \mathrm{min}$. The peptides were eluted by a acetonitrile (ACN) gradient in $10 \mathrm{mM}$ TFA, and $0.5 \mathrm{ml}$ fractions were collected. The major peaks were concentrated and subjected to amino acid sequence analysis.

similar peaks from the posterior-intermediate lobe) indicated that several truncated forms were present, one of which was consistent with the sequence of amidated joining peptide $\mathrm{POMC}(89-105)$.

This study shows, that in the monkey pituitary only low molecular forms of POMC-derived amidated and Cterminal glycine-extended joining peptide are present. The joining peptide is cleaved from the $\mathrm{N}$-terminal part of POMC at the Lys-Arg residues between joining peptide and $\gamma_{3}$ MSH (Fig. 1), and no N-terminal extended forms are present. The joining peptide derived from the posterior-intermediate lobe is to some extent $\mathrm{N}$-terminally truncated by removal of both the glutamate and aspartate, which is probably the reason for the different elution profiles of the joining peptide on HPLC (Fig. 3). The molecular forms of the amidated and glycineextended forms of joining peptide are similar, but the relative amount of joining peptide varies. As low as $6 \%$
TABLE I

AUTOMATED EDMAN DEGRADATION OF JOINING PEPTIDE FROM MONKEY PITUITARY

The amino acid sequences are shown for the major joining peptide peaks. The Glu-Asp-truncated joining peptide detected from the intermediate lobe is not shown in the table. Amino acid sequences consistent with POMC(89-105) were determined for the minor peaks in Fig. 2 (not shown). The yields of the last determined amino acids were approximately $2 \mathrm{pmol}$.

Cycle $\mathrm{AA}^{\mathrm{a}}$ Expected amino Anterior lobe Posterior-intermediate acid lobe

\begin{tabular}{|c|c|c|c|c|}
\hline 1 & 76 & Glu & Glu & $?$ \\
\hline 2 & 77 & Asp & Asp & Asp \\
\hline 3 & 78 & Val & Val & Val \\
\hline 4 & 79 & Ala & Ala & Ala \\
\hline 5 & 80 & Ala & Ala & Ala \\
\hline 6 & 81 & Gly & Gly & Gly \\
\hline 7 & 82 & Glu & Glu & Glu \\
\hline 8 & 83 & Asp & Asp & Asp \\
\hline 9 & 84 & Arg & Arg & $?$ \\
\hline 10 & 85 & Gly & Gly & Gly \\
\hline 11 & 86 & Leu & Leu & Leu \\
\hline 12 & 87 & Leu & Leu & Leu \\
\hline 13 & 88 & Pro & Pro & Pro \\
\hline 14 & 89 & Glu & Glu & Glu \\
\hline 15 & 90 & Gly & Gly & Gly \\
\hline 16 & 91 & Gly & Gly & Gly \\
\hline 17 & 92 & Pro & Pro & Pro \\
\hline 18 & 93 & Glu & Glu & Glu \\
\hline 19 & 94 & Pro & Pro & $?$ \\
\hline 20 & 95 & Arg & $?$ & $?$ \\
\hline $2 \mathrm{l}$ & 96 & Gly & Gly & $?$ \\
\hline 22 & 97 & Asp & Asp & $?$ \\
\hline 23 & 98 & Gly & $?$ & $?$ \\
\hline 24 & 99 & Ala & Ala & $?$ \\
\hline 25 & 100 & Gly & $?$ & $?$ \\
\hline 26 & 101 & Pro & $?$ & $?$ \\
\hline 27 & 102 & Gly & $?$ & $?$ \\
\hline 28 & 103 & Pro & $?$ & $?$ \\
\hline 29 & 104 & Arg & $?$ & $?$ \\
\hline 30 & 105 & Glu- $\mathrm{NH}_{2}$ & $?$ & $?$ \\
\hline
\end{tabular}

a Numbers refer to sequence numbers in monkey POMC [17]. '?' Indicates inconclusive amino acid determination.

of the joining peptide is converted to amidated joining peptide, showing that the amidation reaction is not an efficient process in the case of joining peptide, probably because the penultimate glutamate is a poor substrate for the amidating enzyme [3]. Similar findings have been obtained in human pituitary [11, 12].

The elution position of the joining peptide-immunoreactivities from the BioGel P10 column are somewhat surprising, considering the lower molecular weight of the joining peptide compared with ACTH(1-39) (30 amino acids versus 39 amino acids). A similar elution profile has been detected in human pituitary extracts $[11,12]$. 
The human amidated joining peptide is conjugated through disulfide bridges to, presumably, another joining peptide. However, no cysteine is detected by the sequence analysis in the monkey joining peptides deduced from the cDNA sequence from another monkey, Macaca nemestrina [17]. The explanation for this elution pattern is probably aggregation of the joining peptide, which is also the case for synthetic $\beta$-endorphin in the molecular sieve system used in this study (not shown). However, the exact molecular forms of the joining peptide were unambiguously verified by sequence analysis.

The monkey N-terminal domain of the POMC precursor contains three pairs of dibasic amino acid residues (Fig. 1) which are putative sites for endopeptidase cleavage $[13,15,18]$. Four molecular forms of joining peptide can therefore be imagined disregarding additional analogues due to the possible glycosylation of forms extending to the $\gamma_{1} \mathrm{MSH}$ sequence and beyond $[8,13,18]$. However, only fully processed amidated and glycineextended forms of joining peptide are detected, i.e. joining peptide is cleaved at dibasic amino acids C-terminal to the $\gamma_{3} \mathrm{MSH}$ sequence (Fig. 1). The truncated forms are equivalent to what has been found in human pituitary [11], although only the N-terminal glutamate is removed in the human joining peptide. No truncation has been described in the rat or mouse joining peptide [9]. High molecular forms are not found in monkey pituitary, and less than $1 \%$ of the amidated hinge peptide in human pituitary is $\mathrm{N}$-terminal extended. This would suggest, that cleavage at the $\mathrm{N}$-terminal side of joining peptide in the primates proceeds rapidly and efficiently following the initial cleavage at the dibasic amino acids flanking ACTH(1-39). At present it cannot be decided if the minor peaks of amidated joining peptide are the result of extensive aminopeptidase activity, a proline endopeptidase activity, or metabolic degradation.

We still do not know whether one or several enzymes are involved in dibasic cleavage, but almost complete cleavage at Lys-Arg residues is the favored pattern across species suggesting one single enzyme to be active. While the low molecular weight forms are also the only forms of joining peptides detected in rat and mouse intermediate pituitary lobe, the AtT20 cell line and rat hypothalamus [7, 9], significant amounts of fully N-terminally extended amidated joining peptide have been detected in the rat anterior lobe [9]. This difference can be explained by the substitution of the lysine to an arginine in the $\mathrm{N}$-terminal dibasic residues, thereby decreasing the efficiency of cleavage by a Lys-Arg-cleaving endopeptidase. However, additional deviations from the preferred Lys-Arg cleavage pattern are obvious. Two other Lys-Arg dibasic residues are present in POMC: in $\beta$-LPH at the $\mathrm{N}$-terminal site of $\beta$-endorphin and in
ACTH C-terminal to the $\alpha \mathrm{MSH}$. $\beta$-LPH is cleaved to $\beta$ endorphin in the intermediate lobe cells, but is only cleaved to a minor extent in the anterior lobe. ACTH is processed almost completely to $\alpha \mathrm{MSH}$ in the intermediate lobe, but only very small amounts of cleaved ACTH can be detected in the anterior lobe $[2,4,5,10$, $13]$. These cleavage regions are completely conserved in mammals [17]. It can be imagined that only one endopeptidase is present, but regulated differently by e.g. phosphorylation or cofactors such as calcium (Y.P. Loh, personal communication). Alternatively, more than one enzyme is present, which is specifically activated in different tissues.

In summary, the results show that processing of POMC in the monkey pituitary is very similar to the processing of POMC in the human pituitary. The monkey therefore serves as an accurate model for studying regulation of POMC processing in corticotrophic cells in man.

Dr. Philip Andrews, University of Purdue, Indiana, is acknowledged for performing the amino acid sequence analyses. This study was supported by grants from The Danish Cancer Society and Leo Pharmaceuticals Ltd.

1 Allen, R.G., Hatfield, J.M. and Stack, J., Post-translational processing of pro-opiomelanocortin (POMC)-derived peptides during fetal monkey pituitary development, Dev. Biol. 126 (1988) 156-163.

2 Bjartell, A., Fenger, M., Ekman, R. and Sundler, F., Amidated joining peptide in the human pituitary, gut, adrenal gland and bronchial carcinoids. Immunocytochemical and immunochemical evidence, Peptides 11 (1990) 149-161.

3 Bradbury, A.F., Finnie, M.D.A. and Smyth, D.G., Mechanism of C-terminal amide formation by pituitary enzymes, Nature, 298 (1982) 686-688.

4 Celio, M.R., Pasi, A., Bürgisser, E., Buetti, G., Höllt, V. and Gramsch, C., Proopiocortin fragments in normal human adult pituitary. Distribution and ultrastructural characterization of immunoreactive cells, Acta Endocrinol., 95 (1980) 27-40.

5 Coates, P.J., Doniach, I., Hale, A.C. and Rees, L.H., The distribution of immunoreactive $\alpha$-melanocyte-stimulating hormone cells in the adult human pituitary gland, J. Endocrinol., 111 (1986) 335-342.

6 Crine, P., Seidah, N.G., Routhier, R., Gossard, F. and Chrétien, $M$., Processing of two forms of the common precursor to $\alpha$-melanotropin and $\beta$-endorphin in the rat pars intermedia, Eur. J. Biochem., 110 (1980) 387-396.

7 Emeson, R.B. and Eipper, B.A., Characterization of pro-ACTH/ endorphin-derived peptides in rat hypothalamus, J. Neurosci., 6 (1986) 837-849.

8 Eipper, B.A. and Mains, R.E., Structure and biosynthesis of proadrenocorticotropin/endorphin and related peptides, Endocr. Rev., 1 (1980) 1-27.

9 Eipper, B.A., Park, L., Keutmann, H.T. and Mains, R.E., Amidation of joining peptide, a major pro-ACTH/endorphin-derived product peptide, J. Biol. Chem., 261 (1986) 8686-8694.

10 Fenger, M., Pro-opiomelanocortin-derived peptides in pig pituitary: $\alpha$ - and $\gamma_{1}$-melanocyte-stimulating hormones and their glycine extended precursors, Regul. Pept., 20 (1988) 345-357. 
11 Fenger, M. and Johnsen, A., Alpha-amidated peptides derived from proopiomelanocortin in normal human pituitary, Biochem. J., 250 (1988) 781-788.

12 Fenger, M. and Johnsen, A., Alpha-amidated peptides derived from proopiomelanocortin in human pituitary tumors, J. Endrocrinol., 118 (1988) 329-338.

13 Fenger, M., Proopiomelanocortin: $\alpha$-amidated and related peptides, Scand. J. Clin. Lab. Invest., 50 (1990) 229-245.

14 Hatfield, J.M., Allan, R.G., Stack, J. and Ronnekleiv, O., Posttranslational processing of pro-opiomelanocortin (POMC)-derived peptides during fetal monkey pituitary development, Dev. Biol. 126 (1988) 164-172.

15 Loh, Y.P., Parish, D.C. and Tuteja, R., Purification and characteri- zation of a paired basic residue-specific pro-opiomelanocortin converting enzyme from bovine pituitary intermediate lobe secretory vesicles, J. Biol. Chem., 260 (1985) 7194-7205

16 Meador-Woodruff, J.H., Pellerito, B., Vaudry, H., Jégou, S., Seidah, N.G., Watson, S.J. and Akil, H., Regional processing of the $\mathrm{N}$ - and $\mathrm{C}$-terminal domains of proopiomelanocortin in monkey pituitary and brain, Neuropeptides, 11 (1988) 111-118.

17 Patel, R.D., Sherman, T.G. and Watson, S.J., Characterization of pro-opiomelanocortin cDNA from the old world monkey Macaca nemestrina DNA, 7 (1988) 627-635.

18 Smith, A.I. and Funder, J.W., Proopiomelanocortin processing in the pituitary, central nervous system, and peripheral tissues, Endocr. Rev., 9 (1988) 159-179. 